\title{
High central venous saturation after cardiac surgery is associated with increased organ failure and long-term mortality: an observational cross-sectional study
}

\author{
Felix Balzer ${ }^{1 \dagger}$, Michael Sander ${ }^{1 *}$, Mark Simon ${ }^{2}$, Claudia Spies ${ }^{1}$, Marit Habicher ${ }^{1}$, Sascha Treskatsch ${ }^{1}$, Viktor Mezger ${ }^{1}$,
} Uwe Schirmer ${ }^{4}$, Matthias Heringlake ${ }^{5}$, Klaus-Dieter Wernecke ${ }^{6}$, Herko Grubitzsch $^{3}$ and Christian von Heymann ${ }^{1}$

\begin{abstract}
Introduction: Central venous saturation $\left(\mathrm{S}_{\mathrm{cv}} \mathrm{O}_{2}\right)$ monitoring has been suggested to address the issue of adequate cardiocirculatory function in the context of cardiac surgery. The aim of this study was to determine the impact of low $(\mathrm{L})(<60 \%)$, normal $(\mathrm{N})(60 \%-80 \%)$, and high $(\mathrm{H})(>80 \%) \mathrm{S}_{\mathrm{Cv}} \mathrm{O}_{2}$ measured on intensive care unit (ICU) admission after cardiac surgery.
\end{abstract}

Methods: We conducted a retrospective, cross-sectional, observational study at three ICUs of a university hospital department for anaesthesiology and intensive care. Electronic patient records of all adults who underwent cardiac surgery between 2006 and 2013 and available admission measurements of $\mathrm{S}_{\mathrm{cv}} \mathrm{O}_{2}$ were examined. Patients were allocated to one of three groups according to first $\mathrm{S}_{\mathrm{CV}} \mathrm{O}_{2}$ measurement after ICU admission: group $\mathrm{L}(<60 \%)$, group N (60\%-80\%), and group H (>80\%). Primary end-points were in-hospital and 3-year follow-up survival.

Results: Data from 4,447 patients were included in analysis. Low and high initial measurements of $\mathrm{S}_{\mathrm{cv}} \mathrm{O}_{2}$ were associated with increased in-hospital mortality (L: 5.6\%; N: 3.3\%; H: 6.8\%), 3-year follow-up mortality (L: 21.6\%; $\mathrm{N}:$ 19.3\%; H: 25.8\%), incidence of post-operative haemodialysis (L: 11.5\%; N: 7.8\%; H: 15.3\%), and prolonged hospital length of stay (L: 13 days, 9-22; N: 12 days, 9-19; H: 14 days, 9-21). After adjustment for possible confounding variables, an initial $\mathrm{S}_{\mathrm{cv}} \mathrm{O}_{2}$ above $80 \%$ was associated with adjusted hazard ratios of 2.79 (95\% confidence interval (Cl) 1.565-4.964, $P<0.001$ ) for in-hospital survival and 1.31 (95\% Cl 1.033-1.672, $P=0.026$ ) for 3-year follow-up survival.

Conclusions: Patients with high $\mathrm{S}_{\mathrm{Cv}} \mathrm{O}_{2}$ were particularly affected by unfavourable outcomes. Advanced haemodynamic monitoring may help to identify patients with high $\mathrm{S}_{\mathrm{cv}} \mathrm{O}_{2}$ who developed extraction dysfunction and to establish treatment algorithms to improve patient outcome in these patients.

\section{Introduction}

Postoperative mortality and morbidity of surgical patients are still unsolved puzzles for the clinician [1]. In a multicentre study, the rates of death for patients who underwent surgery varied substantially across hospitals. A recent European study confirmed these results [2,3]. This finding was taken up by initiatives to improve care

\footnotetext{
* Correspondence: michael.sander@charite.de

${ }^{\dagger}$ Equal contributors

'Department of Anesthesiology and Intensive Care Medicine, University Hospital Charité, Campus Charité Mitte/Campus Virchow Klinikum,

Charité-Universitätsmedizin Berlin, Charitéplatz 110098 Berlin, Germany Full list of author information is available at the end of the article
}

for the surgical patient. Worldwide, routine care began including goal-directed optimization in the perioperative period to avoid hypoperfusion and secondary organ failure. According to recent meta-analyses, this strategy showed improved outcomes in the cohort of optimized patients [4]. Nevertheless, this approach will be successful only if the haemodynamic goal still holds.

Cardiac surgery has been shown to be a life-saving procedure in a selected group of patients with coronary heart disease and valve dysfunction [5]. However, this procedure carries a significant risk of death and major complications. In recent years, there has been substantial 
progress in perioperative intensive care management in decreasing the risk for unfavourable outcomes in this group of patients [6,7]. One major step forward was the adoption of early goal-directed, evidence-based haemodynamic treatment strategies in cardiac surgery patients [6]. Goal-directed administration of perioperative fluids has been shown to guarantee the best possible optimization of volume therapy in these patients [8]. Several single-centre studies and meta-analyses have shown improved outcomes by using additional haemodynamic parameters to adjust individual therapy in the perioperative setting [4] of general and cardiac surgery. In cardiac surgery patients in particular, cardiac dysfunction must be detected as early as possible to facilitate adequate therapy using positive inotropic drugs as well as fluids and vasodilators [8].

Central venous saturation $\left(\mathrm{S}_{\mathrm{cv}} \mathrm{O}_{2}\right)$ monitoring has been suggested as one goal to address the issue of adequate cardio-circulatory function in the context of cardiac surgery [6]. This parameter seems especially attractive as venous saturation is readily measurable without additional monitoring technology and is an excellent indicator of the match/mismatch between cardiac output, arterial oxygen saturation, and haemoglobin level as determinants of both oxygen delivery and oxygen consumption. Several studies in the cardiac-surgery patient population and in other surgical specialties have shown that low $\mathrm{S}_{\mathrm{cv}} \mathrm{O}_{2}$ and mixed venous saturation $\left(\mathrm{S}_{\mathrm{v}} \mathrm{O}_{2}\right)$ are associated with unfavourable outcomes $[9,10]$. In addition, high venous saturation has been shown to be associated with increased complication rates in emergency room patients, intensive care unit (ICU) patients, and cardiac-surgery patients [11-13]. However, the results of these studies may be biased by the small number of patients. The aim of this retrospective cross-sectional study, therefore, was to investigate the impact of low, normal, and high $\mathrm{S}_{\mathrm{cv}} \mathrm{O}_{2}$ on postoperative mortality and organ dysfunction in a large cardiac surgery ICU database that reported data from three distinct ICUs at our institution.

\section{Methods}

With the written consent of the federal data protection officer and the hospital ethics commission (ethics committee - Charité - Universitätsmedizin Berlin, EA1/034/ 13), clinical routine data from all patients who underwent cardiac surgery between 2006 and 2013 were extracted from the two electronic patient data management systems at our hospital (COPRA System, Sasbachwalden, Germany, and SAP, Walldorf, Germany) into an anonymized study database. Individual patient consent was waived by the ethics commission. Cardiac surgery was defined as a documented procedure on valves or vessels in proximity to the heart or coronary vessels. Cardiopulmonary bypass and anaesthesia management were performed in accordance with the department's standard operating procedures described in detail elsewhere [14]. Haemodynamic optimization was continuously accomplished in accordance with the German guidelines [6].

To be included in our study, patients had to be admitted postoperatively to one of our three ICUs serving postoperative cardiac surgery patients. Patients who were under the age of 18 by the time of surgery or who had a pulmonary artery catheter were excluded. Patients were grouped on the basis of first measurement of $\mathrm{S}_{\mathrm{cv}} \mathrm{O}_{2}$ after ICU admission as low, normal, or high according to a normal range defined as $60 \%$ to $80 \% . \mathrm{S}_{\mathrm{cv}} \mathrm{O}_{2}$ in the ICU was determined by point-of-care blood gas analysis (ABL800 FLEX; Radiometer, Copenhagen, Denmark). Mortality, length of stay, time of ventilation, renal dysfunction, and days without organ failure were defined as outcome criteria. Information on long-term mortality, defined as 3 years after ICU admission, was acquired, with clearance from the federal data safety officer, by consulting the registry office in Berlin, Germany. Patients with shorter observation intervals (that is, less than 3 years between ICU admission and the date of inquiry at the registry office) were excluded in analyses of long-term mortality. Renal dysfunction was evaluated in accordance with the creatinine criteria of the KDIGO (Kidney Disease: Improving Global Outcomes) clinical practice guidelines for acute kidney injury [15]. Patients with pre-operative haemodialysis were excluded in analysis on renal outcome parameters. Days of organ failure were assessed in accordance with the criteria of the Sequential Organ Failure Assessment score with a tolerance of 1 point in each category (respiration: partial pressure of oxygen/fraction of inspired oxygen $\left(\mathrm{PaO}_{2} /\right.$ $\mathrm{FiO}_{2}$ ) of less than 300; circulation: use of epinephrine or norepinephrine; central nervous system: Glasgow Coma Scale score of less than 13; bilirubin of at least $2.0 \mathrm{mg} /$ $\mathrm{dL}$; kidneys: serum creatinine of at least $2.0 \mathrm{mg} / \mathrm{dL}$ ).

To control for possible confounding variables, we assessed the risk of cardiac surgery by using the Age, Creatinine, and Ejection Fraction (ACEF) risk score by Ranucci et al. [16] and post-operative ICU admission scores-Acute Physiology And Chronic Health Evaluation II (APACHE II) and Therapeutic Intervention Scoring System (TISS) - in addition to basic patient characteristics. The design of this observational cohort study and the results are reported in accordance with the STROBE (Strengthening the Reporting of Observational Studies in Epidemiology) statement [17].

\section{Statistical analysis}

Descriptive analyses and statistical testing were performed by using the $\mathrm{R}$ Project of Statistical Computing 3.0.1. When normal distribution was ruled out by using 
the Kolmogorov-Smirnov test, results were presented as median and interquartile range (IQR) or as mean \pm standard deviation. Qualitative observations were characterized by numbers and percentages. Statistical significance among groups was analysed univariately with the exact non-parametric Kruskal-Wallis test and (pair-wise) with the exact Mann-Whitney $U$ test. Exact chi-squared tests were used for qualitative data. Correlations were evaluated by using Spearman's correlation coefficient. Survival was analysed by using Kaplan-Meier estimations and tested by the log-rank test between groups. Multivariate analysis tested for factors influencing survival. For that purpose, all pre-operative variables, ICU admission scores, and cumulative dosages (first 24 hours in the ICU) of inotropic drugs that showed significant $P$ values in univariate Cox regression were included (besides the grouping) in multivariate Cox regression analyses with stepwise backwards selection. Clinical outcomes with respect to time were analysed by using a non-parametric analysis of longitudinal data in a two-factorial design (first factor: groups; second factor: time). A two-tailed $P$ value of less than 0.05 was considered statistically significant. All tests should be understood as constituting explorative analysis; no adjustment for multiple testing has been made.

\section{Results}

In this retrospective analysis, data from 6,909 patients who underwent cardiac surgery between January 2006 and December 2013 were analysed. There were no records for $\mathrm{S}_{\mathrm{cv}} \mathrm{O}_{2}$ in 1,735 patients, and 697 patients received a pulmonary artery catheter. Both resulted in exclusion from the study, leaving a total of 4,477 patients for analysis. For sub-analysis on long-term survival, complete follow-up data were available for 2,138 patients (Figure 1). In all patients, median $\mathrm{S}_{\mathrm{cv}} \mathrm{O}_{2}$ was 72.2 (IQR 65.5-78.5) with a standard deviation of 9.9 and was measured, on average, within 157 minutes (IQR 81-366) after admission to the ICU.

In 499 patients, $\mathrm{S}_{\mathrm{cv}} \mathrm{O}_{2}$ was less than $60 \%$ (group L), in 3,064 patients $\mathrm{S}_{\mathrm{cv}} \mathrm{O}_{2}$ was between 60 and $80 \%$ (group $\mathrm{N}$ ), and in 914 patients $\mathrm{S}_{\mathrm{cv}} \mathrm{O}_{2}$ was more than $80 \%$ (group $\mathrm{H}$ ) at admission to the ICU after cardiac surgery.

Demographic and surgery-related data are shown in Table 1. Patients with low $\mathrm{S}_{\mathrm{cv}} \mathrm{O}_{2}$ were slightly older than patients from the other two groups. Patients from group $\mathrm{H}$ had significantly lower body mass index compared with the other two groups. The predominant type of surgery was coronary artery bypass graft surgery in all three groups. Duration of anaesthesia and surgery did not differ significantly among groups. APACHE II and TISS scores were significantly higher in group $\mathrm{H}$ compared with reference group $\mathrm{N}$; however, the slight difference (not more than 1 point) might not be considered clinically relevant. Patients from group $\mathrm{H}$ presented a significantly increased ACEF score. Patients from group $\mathrm{H}$ were significantly less frequently diagnosed with coronary heart disease compared with those from group $\mathrm{N}$. Also, patients from group $\mathrm{H}$ were significantly more frequently diagnosed with atrial fibrillation and chronic renal insufficiency than patients from the reference group (Table 1 ).

Patients from group $\mathrm{H}$ had the highest in-hospital mortality (6.8\%), compared with $5.6 \%$ in the group with low $\mathrm{S}_{\mathrm{cv}} \mathrm{O}_{2}$ and $3.3 \%$ in group $\mathrm{N}$ (Table 2). Three-year follow-up data were available for 3,517 out of 4,477

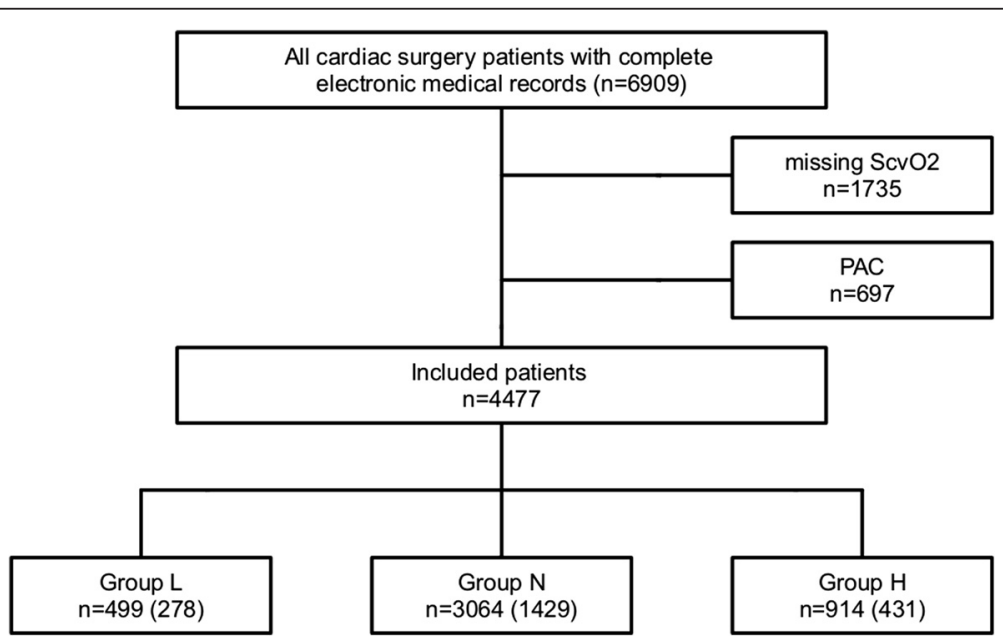

Figure 1 CONSORT (Consolidated Standards Of Reporting Trials) diagram. In the last three boxes containing the number of patients per group who were included in analyses, the parenthesis present the number of patients with complete 3-year follow-up data. PAC, pulmonary artery catheter; $\mathrm{S}_{\mathrm{Cv}} \mathrm{O}_{2}$, central venous saturation. 
Table 1 Patient characteristics

\begin{tabular}{|c|c|c|c|c|}
\hline & Group L & Group N & Group H & Number \\
\hline & $N=499$ & $N=3,064$ & $N=914$ & \\
\hline \multicolumn{5}{|l|}{ Basic data } \\
\hline Age, years & $71.0^{*}(64.0-75.0)$ & $69.0(61.0-75.0)$ & $69.0(61.0-75.0)$ & 4,477 \\
\hline Sex: Female & $149(29.9 \%)$ & $862(28.1 \%)$ & $264(28.9 \%)$ & 4,477 \\
\hline Body mass index & $27.4(24.5-30.6)$ & $27.0(24.4-30.4)$ & $26.4^{*}(23.7-29.6)$ & 3,202 \\
\hline \multicolumn{5}{|l|}{ Surgery } \\
\hline Type of surgery & * & & * & 4,477 \\
\hline CABG & $290(58.1 \%)$ & $1821(59.4 \%)$ & $441(48.2 \%)$ & \\
\hline Valves & $129(25.9 \%)$ & $891(29.1 \%)$ & $367(40.2 \%)$ & \\
\hline Both & $80(16.0 \%)$ & $352(11.5 \%)$ & $106(11.6 \%)$ & \\
\hline Duration of anesthesia, minutes & $290(245-335)$ & $290(240-335)$ & $285(235-330)$ & 3,344 \\
\hline Duration of surgery, minutes & $202(165-245)$ & $200(160-240)$ & $190(155-240)$ & 3,594 \\
\hline Pre-op risk assessment (ACEF) & $1.28(1.14-1.54)$ & $1.27(1.12-154)$ & $1.43^{*}(1.20-1.98)$ & 2,377 \\
\hline \multicolumn{5}{|l|}{ Scores on ICU admission } \\
\hline APACHE ॥ & $18.0(14.0-24.0)$ & $18.0(14.0-24.0)$ & $19.0^{*}(14.0-25.0)$ & 4,008 \\
\hline TISS28 & $36.0(33.0-39.0)$ & $36.0(33.0-39.0)$ & $36.0 *(33.0-40.0)$ & 4,456 \\
\hline \multicolumn{5}{|l|}{ Pre-existing medical conditions } \\
\hline Coronary heart disease & $407(81.6 \%)$ & $2392(78.1 \%)$ & $662^{*}(72.4 \%)$ & 4,477 \\
\hline COPD & $79(15.8 \%)$ & $526(17.2 \%)$ & $172(18.8 \%)$ & 4,477 \\
\hline Diabetes mellitus & $208(41.7 \%)$ & 1,205 (39.3\%) & $369(40.4 \%)$ & 4,477 \\
\hline Peripheral vascular disease & $97(19.4 \%)$ & $611(19.9 \%)$ & $197(21.6 \%)$ & 4,477 \\
\hline Atrial fibrillation & $151(30.3 \%)$ & $859(28.0 \%)$ & $326^{*}(35.7 \%)$ & 4,477 \\
\hline Chronic renal insufficiency & $118(23.6 \%)$ & $696(22.7 \%)$ & $309^{*}(33.8 \%)$ & 4,477 \\
\hline
\end{tabular}

Values are presented as number (percentage) or as median (interquartile range). Significant group differences are displayed as asterisks in columns for groups L (low) and H (high) with reference to group N (normal). ACEF, Age, Creatinine, and Ejection Fraction; APACHE II, Acute Physiology And Chronic Health Evaluation II; CABG, coronary artery bypass graft; COPD, chronic obstructive pulmonary disease; ICU, intensive care unit; TISS28, Therapeutic Intervention Scoring System 28.

included patients. Of these, 1,379 patients were excluded because the interval between surgery and the retrospective data collection was less than 3 years. Results for 3year follow-up mortality show a similar distribution among groups as in-hospital mortality with $19.3 \%$ for group N, 21.6\% for group L, and $25.8 \%$ for group $\mathrm{H}$. Lengths of hospital stay, ICU stay, and postoperative ventilation were significantly longer in patients from group $\mathrm{H}$ compared with patients from group N. Patients from group $\mathrm{H}$ also had the highest rate of renal dysfunction. In keeping with that finding, the incidence of postoperative need for renal replacement therapy (RRT) was $15.3 \%$ in patients with $\mathrm{S}_{\mathrm{cv}} \mathrm{O}_{2}$ above $80 \%$ compared with 9.4\% in group $\mathrm{N}$ and $13.2 \%$ in group L (Table 2). To rule out the time of admission as a confounder for prolonged ventilation, we compared the hours of admission as a binary variable (that is, 8 to 19 versus 20 to 27 hours). No significant difference was found among groups. Outcome parameters are reported separately with respect to the type of surgery that was performed (that is, coronary artery bypass graft, valves, or both) in Additional file 1: Tables S2a-c of the electronic supplement.

In Figure 2, in-hospital mortality in pre-specified subsets of initial $\mathrm{S}_{\mathrm{cv}} \mathrm{O}_{2}$ measurements is shown. There is a U-shaped relationship between initial $\mathrm{S}_{\mathrm{cv}} \mathrm{O}_{2}$ and mortality, showing highest mortality for patients with $\mathrm{S}_{\mathrm{cv}} \mathrm{O}_{2}$ below $60 \%$ and above $80 \%$.

In regard to the use of inotropic medication during the first 24 hours after surgery, patients from group $\mathrm{H}$ received epinephrine more frequently and received enoximone with respectively higher dosages (Table 3 ).

Patients of group $\mathrm{H}$ had significantly elevated levels of lactate, blood glucose, leukocyte count, and procalcitonin (PCT) as inflammation markers in the immediate period after surgery (Table 4). Creatinine, international normalized ratio, and creatine kinase $\mathrm{MB}$ also showed elevated levels in patients of group $\mathrm{H}$. The calculated oxygen extraction rate ranged from 0.15 (IQR 0.12-0.17) in group $\mathrm{H}$ to 0.42 (IQR $0.41-0.46$ ) in group $\mathrm{L}$ ( $P_{\text {groups }}$ $<0.001$ in non-parametric longitudinal analyses). For the 
Table 2 Selected outcome parameters

\begin{tabular}{|c|c|c|c|c|}
\hline & Group L & Group N & Group H & Number \\
\hline & $N=499$ & $N=3,064$ & $N=914$ & \\
\hline \multicolumn{5}{|l|}{ General outcome measures } \\
\hline Mortality (in-hospital) & $28^{*}(5.6 \%)$ & $102(3.3 \%)$ & $62^{*}(6.8 \%)$ & 4,477 \\
\hline Mortality (3-year follow-up) & $60(21.6 \%)$ & $276(19.3 \%)$ & $111^{*}(25.8 \%)$ & 2,138 \\
\hline LOS (hospital), days & $13.0^{*}(9.00-22.0)$ & $12.0(9.00-19.0)$ & $14.0^{*}(9.00-21.0)$ & 4,477 \\
\hline LOS (ICU), days & $6.0^{*}(4.0-9.0)$ & $5.0(3.0-8.0)$ & $6.0^{*}(4.0-100)$ & 4,477 \\
\hline Time of ventilation, hours & $9.0(6.0-16.0)$ & $8.0(5.0-15.0)$ & $12.0 *(7.0-21.0)$ & 4,296 \\
\hline KDIGO & * & & * & 4,165 \\
\hline Stage 0 & $324(70.4 \%)$ & $2288(79.4 \%)$ & 589 (71.5\%) & \\
\hline Stage 1 & $75(16.3 \%)$ & $302(10.5 \%)$ & $86(10.4 \%)$ & \\
\hline Stage 2 & $9(2.0 \%)$ & $49(1.7 \%)$ & $20(2.4 \%)$ & \\
\hline Stage 3 & $52(11.3 \%)$ & $242(8.4 \%)$ & 129 (15.7\%) & \\
\hline KDIGO Stages 1-3 & $136^{*}(29.6 \%)$ & $593(20.6 \%)$ & $235^{*}(28.5 \%)$ & 4,165 \\
\hline Incidence of haemodialysis & $56^{*}(11.5 \%)$ & $235(7.82 \%)$ & $130 *(15.3 \%)$ & 4,344 \\
\hline \multicolumn{5}{|c|}{ Mean percentage of days in the ICU without organ failure } \\
\hline Respiration & $58.0 \% *$ & $64.1 \%$ & $62.7 \%$ & 4,477 \\
\hline Liver & $98.3 \%$ & $98.6 \%$ & $97.8 \%$ & 4,477 \\
\hline Circulation & $48.3 \%^{*}$ & $55.2 \%$ & $50.0 \% *$ & 4,477 \\
\hline Central nervous system & $80.1 \%$ & $83.0 \%$ & $80.5 \%$ & 4,477 \\
\hline Kidneys & $84.7 \% *$ & $88.9 \%$ & $84.4 \%^{*}$ & 4,344 \\
\hline
\end{tabular}

Values are presented as number (percentage) or as median (interquartile range). Significant group differences are displayed as asterisks in columns for groups L (low) and H (high) with reference to group N (normal). Renal dysfunction was assessed in accordance with the KDIGO (Kidney Disease: Improving Global Outcomes) classification, calculating the change in serum creatinine from pre-op until postoperative day 7 . Days of organ failure were calculated according to the criteria of the Sequential Organ Failure Assessment score. Respiration: partial pressure of oxygen/fraction of inspired oxygen $\left(\mathrm{PaO}_{2} / \mathrm{FiO}_{2}\right)$ of less than $300 ;$ bilirubin of at least $2.0 \mathrm{mg} / \mathrm{dL}$; circulation: use of epinephrine or norepinephrine; central nervous system: Glasgow Coma Scale score of less than 13 ; kidneys: serum creatinine of at least $2.0 \mathrm{mg} / \mathrm{dL}$. Patients with pre-operative haemodialysis $(n=133)$ were excluded from analysis of renal outcome parameters. ICU, intensive care unit; LOS, length of stay.

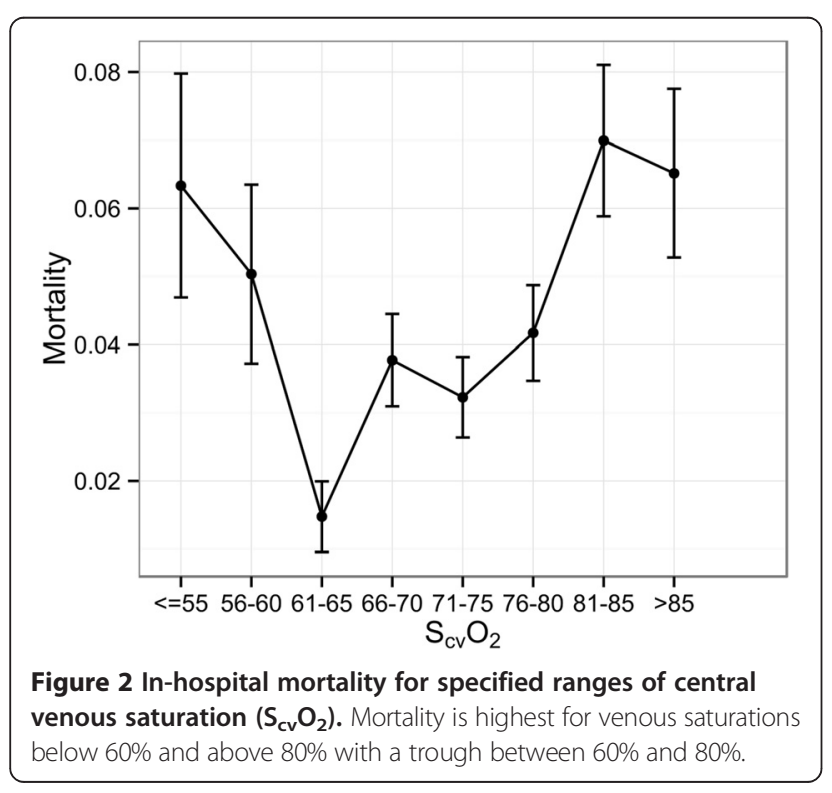

postoperative course of $\mathrm{S}_{\mathrm{cv}} \mathrm{O}_{2}$ and cardiopulmonary basic monitoring, please see Additional file 1: Table S1 in the electronic supplement.

To evaluate multivariately the association of $\mathrm{S}_{\mathrm{cv}} \mathrm{O}_{2}$ with survival, all pre-operative variables, ICU admission scores, and cumulative dosages (first 24 hours in the ICU) of inotropic drugs that showed significant $P$ values in univariate Cox regression were included (besides grouping) in multivariate Cox regression analyses (Table 5). Compared with reference group $\mathrm{N}$, patients from group $\mathrm{H}$ had an almost threefold risk of dying in hospital (hazard ratio 2.79, 95\% confidence interval (CI) 1.565-4.964, $P<0.001)$. The hazard ratio of group $\mathrm{H}$ (compared with $\mathrm{N}$ ) for 3-year follow-up survival was 1.31 (95\% CI 1.033-1.672, $P=$ 0.026 ). When the incidence of pre-operative haemodialysis was included in the regression model as additional explanatory variable, the previously calculated hazard ratios did not change substantially. However, the regression model's quality decreased. Kaplan-Meier curves for 3-year follow-up survival are shown in Figure 3. To investigate whether extraction dysfunction (that is, high $\mathrm{S}_{\mathrm{cv}} \mathrm{O}_{2}$ ) could be predicted by a patient's comorbidities, we developed 
Table 3 Inotropic medication on postoperative day one

\begin{tabular}{|c|c|c|c|c|}
\hline & Group L & Group N & Group H & Number \\
\hline & $N=499$ & $N=3,064$ & $N=914$ & \\
\hline \multicolumn{5}{|l|}{ Norepinephrine } \\
\hline Frequency & $275(55.1 \%)$ & $1,790(58.4 \%)$ & $683^{*}(74.7 \%)$ & 4,477 \\
\hline Dosage, mg/24 hours & $1.17(0.33-3.30)$ & $1.11(0.26-4.08)$ & $2.20 *(0.52-6.58)$ & 2,748 \\
\hline \multicolumn{5}{|l|}{ Epinephrine } \\
\hline Frequency & $63(12.6 \%)$ & 427 (13.9\%) & $384^{*}(42.0 \%)$ & 4,477 \\
\hline Dosage, mg/24 hours & $0.51 *(0.25-2.66)$ & $1.35(0.43-3.23)$ & $1.82^{*}(0.64-4.13)$ & 874 \\
\hline \multicolumn{5}{|l|}{ Dobutamine } \\
\hline Frequency & $317^{*}(63.5 \%)$ & $2,106(68.7 \%)$ & $486^{*}(53.2 \%)$ & 4,477 \\
\hline Dosage, mg/24 hours & $227^{*}(121-382)$ & $190(85.1-321)$ & $134^{*}(53.1-266)$ & 2,909 \\
\hline \multicolumn{5}{|l|}{ Enoximone } \\
\hline Frequency & $84^{*}(16.8 \%)$ & $324(10.6 \%)$ & $229^{*}(25.1 \%)$ & 4,477 \\
\hline Dosage, mg/24 hours & $173(75.4-265)$ & 185 (92.7-294) & $222^{*}(127-305)$ & 637 \\
\hline \multicolumn{5}{|l|}{ Levosimendan } \\
\hline Frequency & $4(0.80 \%)$ & $23(0.75 \%)$ & $17^{*}(1.86 \%)$ & 4,477 \\
\hline Dosage, mg/24 hours & $5.79(3.55-8.11)$ & $7.74(2.85-9.66)$ & 8.50 (5.37-9.38) & 44 \\
\hline
\end{tabular}

Values are presented as number (percentage) or as median (interquartile range). Significant group differences are displayed as asterisks in columns for groups $\mathrm{L}$ (low) and $\mathrm{H}$ (high) with reference to group $\mathrm{N}$ (normal). When a patient was discharged or was deceased during postoperative day 1 , displayed dosages were normalized to 24 hours.

another regression model. However, no significant effect was found $(P>0.05$, data not shown).

\section{Discussion}

In this study, we report haemodynamic and outcome data from a large database including data from three different ICUs serving postoperative cardiac surgery patients. The most important findings of this study were that patients with a presumed 'safe' initial $\mathrm{S}_{\mathrm{cv}} \mathrm{O}_{2}$ above $80 \%$ had the highest in-hospital mortality and the highest mortality in 3-year follow-up. Additionally, these patients showed increased length of mechanical ventilation, a higher incidence of renal dysfunction including increased rate of RRT, evidence of severe postoperative inflammation indicated by increased leukocyte counts and PCT levels, and prolonged lengths of ICU and hospital stay compared with patients with a 'normal' $\mathrm{S}_{\mathrm{cv}} \mathrm{O}_{2} \quad(60 \%$ to $80 \%)$. In the multivariate analysis, patients from group $\mathrm{H}$ had an almost threefold risk of dying in hospital and a 1.3 ratio for 3-year follow-up survival compared with group $\mathrm{N}$.

Patients in the high $\mathrm{S}_{\mathrm{cv}} \mathrm{O}_{2}$ group differed from the other $\mathrm{S}_{\mathrm{cv}} \mathrm{O}_{2}$ groups with respect to the type of surgery and the pre-operative ACEF score and more frequently received inotropic and vasoactive drugs. Also, the patients in the high $\mathrm{S}_{\mathrm{cv}} \mathrm{O}_{2}$ group had more frequent atrial fibrillation as a complication diagnosis. Thus, it was (per se) not astonishing that these patients also had a higher morbidity and mortality. Based on the classic pathophysiological concept, low levels of $\mathrm{S}_{\mathrm{cv}} \mathrm{O}_{2}$ or $\mathrm{S}_{\mathrm{v}} \mathrm{O}_{2}$ are reflective of tissue hypoperfusion and associated with higher complication rates [18]. Our finding that patients with a seemingly 'safe' $\mathrm{S}_{\mathrm{cv}} \mathrm{O}_{2}$ above $80 \%$ showed even worse outcome is in clear contrast to previous studies.

Pre-existing chronic haemodialysis with arterialvenous shunts is known to lead to increased venous saturation. Therefore, a possible explanation for unfavourable outcome in group $\mathrm{H}$ could be this bias as patients with chronic renal failure are known to have an inferior outcome after surgery, including cardiac surgery. However, for this study cohort, this is not the explanation for the observed outcomes in group $\mathrm{H}$ as including incidence of pre-operative haemodialysis with arterial-venous shunts did not result in substantial changes of previously calculated hazard ratios.

Interestingly, the high $\mathrm{S}_{\mathrm{cv}} \mathrm{O}_{2}$ group also presented with significantly increased plasma lactate levels. It is well accepted that increased lactate levels are associated with increased mortality after cardiac surgery [19]. Furthermore, it is of note that a recent retrospective study revealed a link between elevated lactate levels during normal or even high $\mathrm{S}_{\mathrm{cv}} \mathrm{O}_{2}$ and unfavourable outcome [20]. In that study with 629 patients, elevated lactate levels in the setting of a normal $\mathrm{S}_{\mathrm{cv}} \mathrm{O}_{2}$ were associated with significantly higher incidence of major complications. However, high lactate levels not only may be 
Table 4 Postoperative laboratory data

\begin{tabular}{|c|c|c|c|c|}
\hline & Group L & Group N & Group H & Number \\
\hline & $N=499$ & $N=3,064$ & $N=914$ & \\
\hline Lactate, $\mathrm{mg} / \mathrm{dL}$ & & & * & \\
\hline $0-6$ hours & $15.0(10.0-21.0)$ & $15.0(10.0-22.0)$ & $22.0^{*}(12.0-50.8)$ & 4,188 \\
\hline $6-12$ hours & $14.0(10.0-20.0)$ & $14.0(10.0-21.0)$ & $16.0^{*}(10.0-26.0)$ & 4,254 \\
\hline $12-18$ hours & $11.0(9.00-15.0)$ & $11.0(9.00-16.0)$ & $12.0^{*}(9.00-17.0)$ & 4,274 \\
\hline 18-24 hours & $12.0(9.00-16.0)$ & $12.0(9.00-16.0)$ & $12.0(9.00-16.0)$ & 4,335 \\
\hline Blood glucose, $\mathrm{mg} / \mathrm{dL}$ & * & & & \\
\hline $0-6$ hours & $142 *(123-164)$ & $148(129-169)$ & $152^{*}(126-184)$ & 4,188 \\
\hline $6-12$ hours & $132 *(117-149)$ & 135 (119-153) & $137^{*}(119-158)$ & 4,254 \\
\hline $12-18$ hours & $128(112-146)$ & $131(116-146)$ & $129(112-148)$ & 4,254 \\
\hline 18-24 hours & $136(118-156)$ & $137(120-157)$ & $135(118-158)$ & 4,335 \\
\hline Haemoglobin, g/dL & * & & & \\
\hline POD 0 & $10.0^{*}(9.30-10.8)$ & $10.3(9.50-11.1)$ & $10.3(9.50-11.3)$ & 4,350 \\
\hline POD 1 & $9.70(9.10-10.4)$ & $9.70(9.00-10.5)$ & $9.80(9.10-10.6)$ & 4,477 \\
\hline POD 2 & $9.60(9.10-10.4)$ & $9.70(9.00-10.4)$ & $9.70(9.10-10.4)$ & 4,477 \\
\hline POD 3 & $9.70(9.20-10.5)$ & $9.80(9.20-10.6)$ & $9.80(9.20-10.6)$ & 4,477 \\
\hline Leukocytes, /nL & & & * & \\
\hline POD 0 & $12.0(9.48-15.4)$ & $12.4(9.75-15.5)$ & $13.2^{*}(10.1-16.8)$ & 4,171 \\
\hline POD 1 & $13.1(10.7-16.6)$ & $13.8(11.0-16.7)$ & $14.4^{*}(11.3-17.8)$ & 4,413 \\
\hline POD 2 & $13.6(11.0-16.9)$ & $14.0(11.2-17.1)$ & $14.9^{*}(11.6-18.6)$ & 4,439 \\
\hline POD 3 & $11.9(9.27-15.0)$ & $11.6(9.36-14.4)$ & $12.0^{*}(9.50-15.6)$ & 4,446 \\
\hline Procalcitonin, $\mu \mathrm{g} / \mathrm{L}$ & & & * & \\
\hline POD 0 & $0.48(0.48-0.49)$ & $0.58(0.14-1.41)$ & $1.70(0.27-5.87)$ & 22 \\
\hline POD 1 & $1.63(0.39-3.98)$ & $1.80(0.56-5.28)$ & $4.19^{*}(1.62-11.8)$ & 194 \\
\hline POD 2 & $1.06(0.34-4.90)$ & $1.52(0.40-5.45)$ & $4.37^{*}(1.50-11.9)$ & 562 \\
\hline POD 3 & $1.00(0.34-3.27)$ & $0.90(0.30-3.57)$ & $3.05^{*}(0.80-8.45)$ & 979 \\
\hline Alanine transaminase, $\mathrm{U} / \mathrm{L}$ & & & * & \\
\hline POD 0 & $22.0(16.0-31.0)$ & $22.0(16.0-33.0)$ & $23.0(16.0-35.0)$ & 3,999 \\
\hline POD 1 & $24.0(17.0-35.0)$ & $23.0(17.0-35.0)$ & $24.0(17.0-38.0)$ & 4,336 \\
\hline POD 2 & $24.0(18.0-38.0)$ & $24.0(17.0-35.0)$ & $25.0^{*}(18.0-39.0)$ & 4,389 \\
\hline POD 3 & $25.5(18.0-39.0)$ & $24.0(17.0-36.0)$ & $25.0(18.0-40.0)$ & 4,401 \\
\hline Creatinine, $\mathrm{mg} / \mathrm{dL}$ & * & & * & \\
\hline Last preop & $1.02 *(0.86-1.20)$ & $0.98(0.83-1.18)$ & $1.08^{*}(0.88-1.35)$ & 4,322 \\
\hline POD 1 & $1.14^{*}(0.91-1.52)$ & $1.06(0.86-1.37)$ & $1.19 *(0.93-1.73)$ & 4,412 \\
\hline POD 2 & $1.15^{*}(0.90-1.55)$ & $1.04(0.82-1.42)$ & $1.20^{*}(0.90-1.77)$ & 4,442 \\
\hline POD 3 & $1.11^{*}(0.85-1.48)$ & $1.00(0.80-1.37)$ & $1.16^{*}(0.86-1.70)$ & 4,449 \\
\hline International normalized ratio & * & & * & \\
\hline POD 0 & $1.31(1.22-1.43)$ & $1.30(1.22-1.40)$ & $1.33^{*}(1.23-1.45)$ & 4,153 \\
\hline POD 1 & $1.27(1.19-1.37)$ & $1.26(1.18-1.35)$ & $1.28^{*}(1.20-1.39)$ & 4,412 \\
\hline POD 2 & $1.26^{*}(1.19-1.37)$ & $1.25(1.18-1.35)$ & $1.27^{*}(1.19-1.39)$ & 4,437 \\
\hline POD 3 & $1.24^{*}(1.15-1.34)$ & $1.21(1.13-1.31)$ & $1.23^{*}(1.14-1.35)$ & 4,445 \\
\hline
\end{tabular}


Table 4 Postoperative laboratory data (Continued)

\begin{tabular}{|c|c|c|c|c|}
\hline Creatine kinase $\mathrm{MB}, \mathrm{U} / \mathrm{L}$ & $*$ & & * & \\
\hline POD 0 & $38.0 *(27.0-55.5)$ & $34.0(26.0-52.0)$ & $38.0 *(26.0-61.0)$ & 3,913 \\
\hline POD 1 & $33.0^{*}(22.0-56.0)$ & $31.0(22.0-51.0)$ & $33.0 *(22.0-58.0)$ & 4,191 \\
\hline POD 2 & $27.0 *(19.0-46.0)$ & $24.0(17.0-39.0)$ & $25.0(17.0-43.0)$ & 4,222 \\
\hline POD 3 & $23.5^{*}(16.0-38.0)$ & $21.0(15.0-33.0)$ & $21.0(15.0-35.0)$ & 4,233 \\
\hline
\end{tabular}

reflective of tissue hypoperfusion (that is, anaerobic metabolism leading to lactic acidosis type A) but also may be induced by factors stimulating glycogenolysis, glycolysis, and hyperglycemia (that is, lactic acidosis type B). It is of note that epinephrine is an important trigger for the latter effects [21] and that the patients in the high $\mathrm{S}_{\mathrm{cv}} \mathrm{O}_{2}$ group more frequently received norepinephrine and epinephrine than the normal and the low $\mathrm{S}_{\mathrm{cv}} \mathrm{O}_{2}$ groups, suggesting that the hyperlactatemia may be, at least in part, an effect of catecholamine treatment.

Additionally, as we found a significant higher occurrence of epinephrine application in group $\mathrm{H}$, it cannot be ruled out that the use of epinephrine aggravates the shunting effects in postoperative cardiac surgery patients. If so, the question of whether epinephrine is what we are aiming for or just creates good numbers in the charts (for example, higher cardiac index and higher mean arterial pressure) clearly arises.

Totaro and Raper [22] have shown that 30\% of patients receiving epinephrine after cardiac surgery developed lactic acidosis but that plasma lactate remained unchanged in patients who received norepinephrine. Comparably, small observational studies and case reports have shown an association between epinephrine use and hyperlactatemia [23]. A small randomized trial in cardiac surgery patients with postoperative lowcardiac output syndrome revealed significantly increased glucose and lactate levels and an increased lactatepyruvate ratio in patients who received epinephrine in comparison with milrinone treatment, suggesting that epinephrine not only stimulated glycogenesis but also led to a situation with tissue malperfusion and anaerobic metabolism despite improved haemodynamics [24]. In line with this, Levy et al. [25] have shown that muscle tissue is a major source of lactate in patients with sepsis during treatment with epinephrine. The authors showed that patients with septic shock had increased skeletal muscle lactate production and that these metabolic alterations could be blocked by the $\mathrm{Na}^{+} / \mathrm{K}^{+}$-ATPase blocker ouabain, suggesting that the increased lactate levels were of a metabolic nature. Nonetheless, the lower oxygen extraction in the high $\mathrm{S}_{\mathrm{cv}} \mathrm{O}_{2}$ group clearly suggests that-besides the metabolic effects of the infused catecholamines-tissue hypoperfusion may be another important component explaining the significantly increased rate of organ dysfunction and the higher mortality.

The concept of venous saturation monitoring to guide haemodynamic therapy is neither new nor peculiar. The first reports that used venous saturation monitoring to guide therapy in critically ill patients date back to the last century [26]. Accordingly, several reviews on this topic have been published in recent years $[8,9]$ and concluded that venous saturation measurements may be used to monitor the adequacy of the circulation and to guide haemodynamic therapy in the perioperative period [4]. Venous saturation depends on the balance between oxygen delivery with its covariates-arterial oxygen saturation, cardiac output, and haemoglobin level-and oxygen consumption. With some limitations, $\mathrm{S}_{\mathrm{cv}} \mathrm{O}_{2}$ can be used as a substitute for $\mathrm{S}_{\mathrm{v}} \mathrm{O}_{2}[8,10]$. In clinical practice, $\mathrm{S}_{\mathrm{cv}} \mathrm{O}_{2}$ is often measured as the use of pulmonary arterial catheters in the context of critical illness; surgery has declined over the last decade [27].

Studies using venous saturation as a goal to optimize patients in the ICU reported beneficial results. In the landmark study by Rivers et al., performed in patients with severe sepsis and septic shock, this concept has been shown to decrease mortality in the patient group undergoing a treatment algorithm aiming for an $\mathrm{S}_{\mathrm{cv}} \mathrm{O}_{2}$ of at least $70 \%$ [28]. Another study in a cardiac surgery patient population reported a decreased overall complication rate in patients optimized to an $\mathrm{S}_{\mathrm{v}} \mathrm{O}_{2}$ of at least $70 \%$ and lactate below $2.0 \mathrm{mmol} / \mathrm{L}$ during ICU treatment after surgery [29]. In that study, patients of the protocol group had a shorter length of stay in the hospital and overall morbidity was lower by the time of hospital discharge.

In older as well as in recent studies, low $\mathrm{S}_{\mathrm{cv}} \mathrm{O}_{2}$ and $\mathrm{S}_{\mathrm{v}} \mathrm{O}_{2}$ were linked to unfavourable outcomes [11-13,30]. Thus, our finding of unfavourable outcomes in patients with $\mathrm{S}_{\mathrm{cv}} \mathrm{O}_{2}$ below $60 \%$ is in line with previous reports. A study by Perz et al. investigated venous saturation measurements after cardiac surgery [13], indicating that an $\mathrm{S}_{\mathrm{cv}} \mathrm{O}_{2}$ below $60.8 \%$ in patients undergoing cardiac surgery was associated with an unfavourable outcome. 
Table 5 Multivariate Cox regression analysis for short- and long-term survival

\begin{tabular}{|c|c|c|c|c|}
\hline & \multicolumn{2}{|c|}{ Cox regression for in-hospital survival } & \multicolumn{2}{|c|}{ Cox regression for 3-year follow-up survival } \\
\hline & HR unadjusted & HR adjusted & HR unadjusted & HR adjusted \\
\hline \multirow[t]{2}{*}{ Group L, $\mathrm{S}_{\mathrm{cv}} \mathrm{O}_{2}<60$} & $1.377(0.905-2.096)$ & $2.124(0.985-4.582)$ & $1.126(0.911-1.392)$ & 1.209 (0.893-1.638), \\
\hline & $P=0.135$ & $P=0.055$ & $P=0272$ & $P=0.220$ \\
\hline \multirow[t]{2}{*}{ Group $\mathrm{H}_{1} \mathrm{~S}_{\mathrm{CV}} \mathrm{O}_{2}>80$} & 1.709 (1.244-2.348), & $2.787(1.565-4.964)$ & $1.462(1.244-1.718)$ & $1.314(1.033-1.672)$ \\
\hline & $P=0.001$ & $P<0.001$ & $P<0.001$ & $P=0.026$ \\
\hline \multirow[t]{2}{*}{ Age in years } & $1.039(1.023-1.056)$ & $1.096(1.056-1.138)$ & $1.050(1.041-1.058)$ & $1.044(1.029-1.059)$ \\
\hline & $P<0.001$ & $P<0.001$ & $P<0.001$ & $P<0.001$ \\
\hline \multirow[t]{2}{*}{ Type of surgery: valves } & $1.480(1.083-2.022)$ & $1.858(0.991-3.458)$ & $1.596(1.369-1.860)$ & $1.438(1.124-1.840)$ \\
\hline & $P=0.014$ & $P=0.054$ & $P<0.001$ & $P=0.004$ \\
\hline \multirow[t]{2}{*}{ Type of surgery: $C A B G$ + valves } & 1.469 (0.978-2.207), & $1.747(0.846-3.608)$ & $1.835(1.519-2.218)$ & $1.281(0.961-1.703)$ \\
\hline & $P=0.064$ & $P=0.132$ & $P<0.001$ & $P=0.088$ \\
\hline \multirow[t]{2}{*}{ Duration of surgery, minutes } & & & $1.003(1.002-1.004)$ & $1.002(1.001-1.004)$ \\
\hline & & & $P<0.001$ & $P=0.010$ \\
\hline \multirow[t]{2}{*}{ Pre-operative ACEF score } & & & $2.609(2.232-3.050)$ & $1.379(1.124-1.693)$ \\
\hline & & & $P<0.001$ & $P=0.002$ \\
\hline \multirow[t]{2}{*}{ APACHE II score on ICU admission } & & & 1.049 (1.039-1.060), & $1.030(1.014-1.047)$ \\
\hline & & & $P<0.001$ & $P<0.001$ \\
\hline \multirow[t]{2}{*}{ TISS score on ICU admission } & 1.088 (1.069-1.107), & $1.100(1.060-1.142)$ & $1.056(1.045-1.068)$ & $1.028(1.009-1.047)$ \\
\hline & $P<0.001$ & $P<0.001$ & $P<0.001$ & $P=0.004$ \\
\hline \multirow[t]{2}{*}{ Atrial fibrillation } & & & $2.147(1.869-2.466)$ & $1.674(1.340-2.091)$ \\
\hline & & & $P<0.001$ & $P<0.001$ \\
\hline \multirow[t]{2}{*}{ COPD } & & & $1.798(1.538-2.102)$ & 1.497 (1.173-1.910), \\
\hline & & & $P<0.001$ & $P=0.001$ \\
\hline \multirow[t]{2}{*}{ Diabetes mellitus } & 1.440 (1.070-1.939), & $2.076(1.173-3.675)$ & 1.735 (1.512-1.990), & $1.405(1.137-1.736)$ \\
\hline & $P=0.016$ & $P=0.012$ & $P<0.001$ & $P=0.002$ \\
\hline \multirow[t]{2}{*}{ Peripheral vascular disease } & 1.485 (1.100-2.006), & $1.835(1.064-3.164)$ & $1.865(1.601-2.174)$ & $1.733(1.364-2.201)$ \\
\hline & $P=0.010$ & $P=0.029$ & $P<0.001$ & $P<0.001$ \\
\hline \multirow[t]{2}{*}{ Dobutamine, cumulative dosage $\mathrm{mg} / 24$ hours } & & & 0.999 (0.998-0.999), & 0.999 (0.999-1.000), \\
\hline & & & $P<0.001$ & $P=0.098$ \\
\hline \multirow[t]{2}{*}{ Enoximone, cumulative dosage $\mathrm{mg} / 24$ hours } & & & $1.000(1.000-1.000)$ & 0.999 (0.998-1.000), \\
\hline & & & $P=0.002$ & $P=0.144$ \\
\hline \multirow[t]{2}{*}{ Norepinephrine, cumulative dosage $\mathrm{mg} / 24$ hours } & $1.014(1.012-1.017)$ & $1.018(1.011-1.024)$ & $1.015(1.012-1.017)$ & $1.016(1.011-1.021)$ \\
\hline & $P<0.001$ & $P<0.001$ & $P<0.001$ & $P<0.001$ \\
\hline
\end{tabular}

Values are presented as median (interquartile range). Hazard ratios (HRs) are adjusted for all pre-operative variables, intensive care unit (ICU) admission scores, and cumulative dosages (first 24 hours in ICU) of inotropic drugs that were significant in univariate Cox regression. Variables have been selected by using stepwise backward selection. Reference for type of surgery: coronary artery bypass graft (CABG); for grouping variable: group $\mathrm{N}\left(60 \leq \mathrm{S}_{\mathrm{cv}} \mathrm{O}_{2} \leq 80\right)$. $\mathrm{ACEF}, \mathrm{Age}, \mathrm{Creatinine}$, and

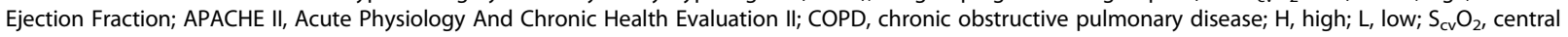
venous saturation; TISS, Therapeutic Intervention Scoring System.

However, optimizing venous saturation above a certain cutoff may carry some risks that lie within the physiology of venous saturations. Our finding of increased mortality and complication rate in patients with $\mathrm{S}_{\mathrm{cv}} \mathrm{O}_{2}$ above $80 \%$ accords with smaller reports from critically ill patients and from patients after cardiac surgery.

Pope et al. reported data from 619 emergency department (ED) patients. In regard to the maximum $\mathrm{S}_{\mathrm{cv}} \mathrm{O}_{2}$ during treatment in the ED, mortality rates of both the hypoxia group $(40 \%)$ and the hyperoxia group (34\%) were significantly higher than the rate of mortality in the normoxia group (21\%) [11]. Therefore, in line with our results in cardiac surgery patients, central venous hyperoxia in ED patients with suspected sepsis seems to be associated with unfavourable outcomes as well. Yet another study provided evidence that hyperoxia in patients 


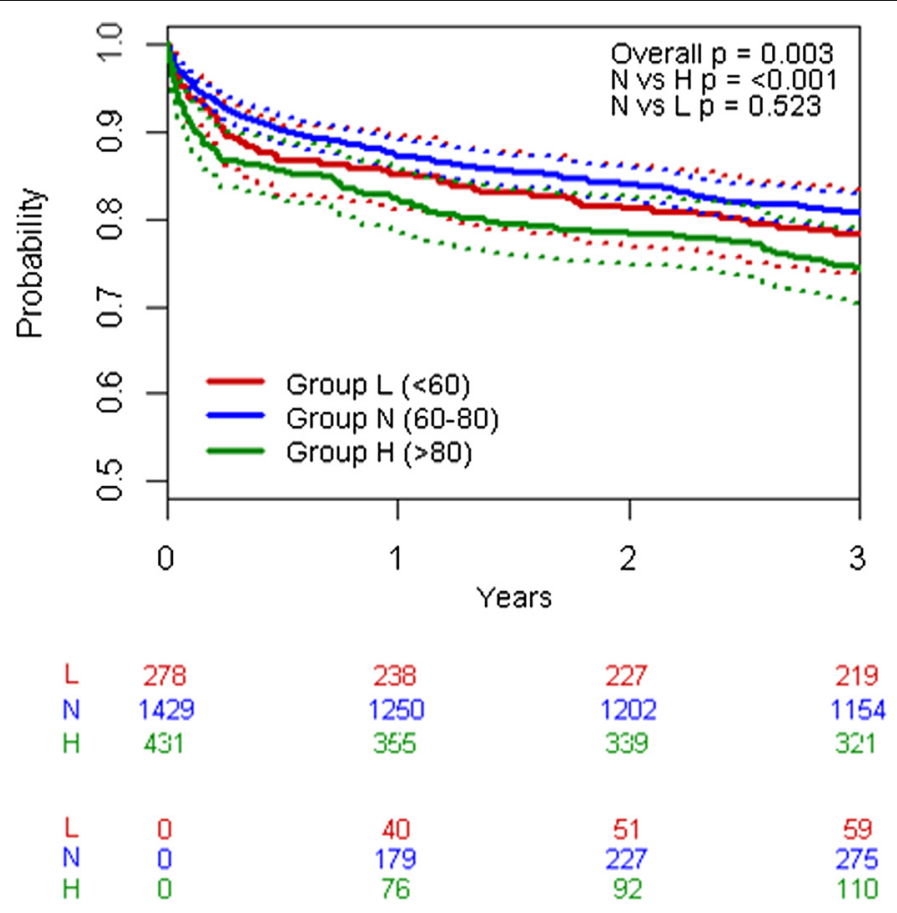

Figure 3 Kaplan-Meier curves for long-term survival (3-year follow-up) of groups $\mathrm{L}\left(\mathrm{S}_{\mathrm{cv}} \mathrm{O}_{2}<60 \%\right), \mathrm{N}\left(60 \% \leq \mathrm{S}_{\mathrm{cv}} \mathrm{O}_{2} \leq 80 \%\right)$, and $\mathrm{H}$ $\left(\mathrm{S}_{\mathrm{cv}} \mathrm{O}_{2}>\mathbf{8 0} \%\right)$. Only patients with a minimal observation period of 3 years were included. Patients from groups $\mathrm{N}$ and $\mathrm{H}$ differed significantly in pair-wise testing (log-rank test: $P<0.001)$. $\mathrm{H}$, high; $\mathrm{L}$, low; $\mathrm{N}$, normal; $\mathrm{S}_{\mathrm{cv}} \mathrm{O}_{2}$, central venous saturation.

with sepsis is linked with unfavourable outcomes [12]. That study retrospectively analysed data from all ICU admissions of patients with septic shock and reported the maximum $\mathrm{S}_{\mathrm{cv}} \mathrm{O}_{2}$ within the first 72 hours after the onset of shock. In conclusion, high levels of $\mathrm{S}_{\mathrm{cv}} \mathrm{O}_{2}$ (more than $80 \%)$ in the first 72 hours after resuscitating patients in septic shock were associated with increased mortality which might reflect an impaired use of oxygen as evidenced by increased lactate levels [12].

\section{Limitations}

Owing to the retrospective nature of our data, it is possible only to report associations and not causality. Therefore, we can only speculate about possible mechanisms leading to the increased complication and mortality rate in the group with high venous saturation measurements after cardiac surgery. Also, we cannot exclude that changes in management between 2006 and 2013 contributed to this finding. One further point of concern might be that $\mathrm{S}_{\mathrm{cv}} \mathrm{O}_{2}$ measurements after admission to the ICU were missing in about one fourth of the total population. However, this seems negligible as baseline characteristics of all patients undergoing cardiac surgery regardless of effectuated $\mathrm{S}_{\mathrm{cv}} \mathrm{O}_{2}$ measurements did not differ statistically (data not shown).

Nevertheless, we believe that it is important to provide evidence that high venous saturation measurements should not be misinterpreted as safe but should be considered to be associated with increased mortality and complication rates. Additionally, despite the increasing use of $\mathrm{S}_{\mathrm{cv}} \mathrm{O}_{2}$ in clinical practice, several lines of evidence point out that, at least during states of increased oxygen extraction $[10,20]$, the difference between $\mathrm{S}_{\mathrm{cv}} \mathrm{O}_{2}$ and $\mathrm{S}_{\mathrm{v}} \mathrm{O}_{2}$ may increase. In these situations, $\mathrm{S}_{\mathrm{cv}} \mathrm{O}_{2}$ levels do not reliably reflect the 'true' systemic balance between oxygen delivery and demand. Nonetheless, with respect to the frequent use of $\mathrm{S}_{\mathrm{cv}} \mathrm{O}_{2}$ in routine practice [27] and current recommendations for the use of $\mathrm{S}_{\mathrm{cv}} \mathrm{O}_{2}$ for titrating haemodynamic therapy in cardiac surgery patients [6], the findings of the present study have relevant practical implications.

\section{Conclusions}

We demonstrated that patients after cardiac surgery presenting with an initial $\mathrm{S}_{\text {cv }} \mathrm{O}_{2}$ higher than $80 \%$ on ICU admission-which might be considered safe or even optimal-had the highest in-hospital mortality and highest mortality in 3-year follow-up. This group also had increased lengths of ICU and hospital stay, increased mechanical ventilation after surgery, and increased rates of postoperative renal dysfunction and failure. Increased inflammation markers in patients with an initial $\mathrm{S}_{\mathrm{cv}} \mathrm{O}_{2}$ higher than $80 \%$ might point to a postoperative 'sepsislike' syndrome with oxygen extraction dysfunction. 
Therefore, it seems indicated that additional advanced haemodynamic monitoring may help to identify patients with high $\mathrm{S}_{\mathrm{cv}} \mathrm{O}_{2}$ who developed extraction dysfunction and to establish treatment algorithms in order to improve outcome.

\section{Key messages}

- In this study, we describe a statistically significant association between an initial $\mathrm{S}_{\mathrm{cv}} \mathrm{O}_{2}$ higher than $80 \%$ on ICU admission after cardiac surgery and an increased in-hospital and 3-year follow-up mortality.

- Additional haemodynamic monitoring may help to identify patients with high $\mathrm{S}_{\mathrm{cv}} \mathrm{O}_{2}$ who developed oxygen extraction dysfunction and to establish treatment algorithms in these patients to improve outcome.

\section{Additional file}

\section{Additional file 1: Supplementary tables for results section.}

\author{
Abbreviations \\ ACEF: Age, Creatinine, and Ejection Fraction; APACHE II: Acute Physiology \\ And Chronic Health Evaluation II; Cl: confidence interval; ED: emergency \\ department; H: high; ICU: intensive care unit; IQR: interquartile range; L: low; \\ $\mathrm{N}$ : normal; PCT: procalcitonin; RRT: renal replacement therapy; $\mathrm{S}_{\mathrm{cv}} \mathrm{O}_{2}$ : central \\ venous saturation; $\mathrm{S}_{\mathrm{V}} \mathrm{O}_{2}$ : mixed venous saturation; TISS: Therapeutic \\ Intervention Scoring System.
}

\section{Competing interests}

The authors declare that they have no competing interests.

\begin{abstract}
Authors' contributions
FB performed data collection and statistical analysis; drafted parts of the manuscript; shared responsibility for design, coordination, and finalization of the manuscript; and had full access to the data. MSa outlined the study design; drafted parts of the manuscript; shared responsibility for design, coordination, and finalization of the manuscript; and had full access to the data. K-DW contributed to the design of the study regarding statistical analysis, was involved in drafting the Methods section, and critically revised the manuscript. MSi, CS, MHa, ST, VM, US, and MHe contributed to the Discussion section from the point of view of perioperative and intensive care medicine. CvH contributed to the Discussion section from the point of view of perioperative and intensive care medicine and shared responsibility for design, coordination, and finalization of the manuscript. HG contributed from a cardiac surgeon's perspective. All authors read and approved the final manuscript.
\end{abstract}

\section{Acknowledgements}

This study has been supported by an institutional grant of Charité Medical School. No external funding source has been involved.

\section{Author details}

'Department of Anesthesiology and Intensive Care Medicine, University Hospital Charité, Campus Charité Mitte/Campus Virchow Klinikum, Charité-Universitätsmedizin Berlin, Charitéplatz 110098 Berlin, Germany. ${ }^{2}$ Department of Anaesthesiology and Intensive Care Medicine, Jena University Hospital, Erlanger Allee 101, 07747 Jena, Germany. ${ }^{3}$ Department of Cardiovascular Surgery, University Hospital Charité, Campus Charité Mitte/ Campus Virchow Klinikum, Charité-Universitätsmedizin Berlin, Charitéplatz 1, 10098 Berlin, Germany. ${ }^{4}$ Institute of Anaesthesiology Heart and Diabetes Center Nordrhein-Westfalen, University Clinic Ruhr-University Bochum, Georgstrasse 11, 32545 Bad Oeynhausen, Germany. ${ }^{5}$ Department of Anaesthesiology and Intensive Care Medicine, University of Lübeck,
Ratzeburger Allee 160, 23538 Lübeck, Germany. ${ }^{6}$ SOSTANA GmbH, Wildensteiner Straße 27, 10318 Berlin, Germany.

Received: 2 December 2014 Accepted: 17 March 2015

Published online: 16 April 2015

\section{References}

1. Weiser TG, Regenbogen SE, Thompson KD, Haynes AB, Lipsitz SR, Berry WR, et al. An estimation of the global volume of surgery: a modelling strategy based on available data. Lancet. 2008;372:139-44.

2. Ghaferi AA, Birkmeyer JD, Dimick JB. Variation in hospital mortality associated with inpatient surgery. N Engl J Med. 2009;361:1368-75.

3. Pearse RM, Moreno RP, Bauer P, Pelosi P, Metnitz P, Spies C, et al. Mortality after surgery in Europe: a 7 day cohort study. Lancet. 2012;380:1059-65.

4. Grocott MP, Dushianthan A, Hamilton MA, Mythen MG, Harrison D, Rowan $\mathrm{K}$, et al. Perioperative increase in global blood flow to explicit defined goals and outcomes following surgery. Cochrane Database Syst Rev. 2012;11:CD004082

5. Serruys PW, Morice M-C, Kappetein AP, Colombo A, Holmes DR, Mack MJ, et al. Percutaneous coronary intervention versus coronary-artery bypass grafting for severe coronary artery disease. N Engl J Med. 2009;360:961-72.

6. Carl M, Alms A, Braun J, Dongas A, Erb J, Goetz A, et al. S3 guidelines for intensive care in cardiac surgery patients: haemodynamic monitoring and cardiocirculary system. Ger Med Sci. 2010;8:12.

7. Goepfert MS, Richter HP, Zu Eulenburg C, Gruetzmacher J, Rafflenbeul E, Roeher K, et al. Individually optimized haemodynamic therapy reduces complications and length of stay in the intensive care unit: a prospective, randomized controlled trial. Anesthesiology. 2013;119:824-36.

8. Habicher M, Perrino A, Spies CD, Von Heymann C, Wittkowski U, Sander M. Contemporary fluid management in cardiac anesthesia. J Cardiothorac Vasc Anesth. 2011;25:1141-53.

9. Shepherd SJ, Pearse RM. Role of central and mixed venous oxygen saturation measurement in perioperative care. Anesthesiology. 2009;111:649-56.

10. Sander M, Spies CD, Foer A, Weymann L, Braun J, Volk T, et al. Agreement of central venous saturation and mixed venous saturation in cardiac surgery patients. Intensive Care Med. 2007;33:1719-25.

11. Pope JV, Jones AE, Gaieski DF, Arnold RC, Trzeciak S, Shapiro NI, et al. Multicenter study of central venous oxygen saturation $(\mathrm{ScvO}(2))$ as a predictor of mortality in patients with sepsis. Ann Emerg Med. 2010;55:40-46.e1.

12. Textoris J, Fouché L, Wiramus S, Antonini F, Tho S, Martin C, et al. High central venous oxygen saturation in the latter stages of septic shock is associated with increased mortality. Crit Care. 2011;15:R176.

13. Perz S, Uhlig T, Kohl M, Bredle DL, Reinhart K, Bauer M, et al. Low and 'supranormal' central venous oxygen saturation and markers of tissue hypoxia in cardiac surgery patients: a prospective observational study. Intensive Care Med. 2011;37:52-9.

14. Sander M, Spies CD, Martiny V, Rosenthal C, Wernecke K-D, Von Heymann C. Mortality associated with administration of high-dose tranexamic acid and aprotinin in primary open-heart procedures: a retrospective analysis. Crit Care. 2010;14:R148.

15. Kellum JA, Lameire N. for the KDIGO AKI Guideline Work Group. Diagnosis, evaluation, and management of acute kidney injury: a KDIGO summary (Part 1). Crit Care. 2013;17:204

16. Ranucci M, Castelvecchio S, Conte M, Megliola G, Speziale G, Fiore F, et al. The easier, the better: age, creatinine, ejection fraction score for operative mortality risk stratification in a series of 29,659 patients undergoing elective cardiac surgery. J Thorac Cardiovasc Surg. 2011;142:581-6.

17. von Elm E, Altman DG, Egger M, Pocock SJ, Gøtzsche PC, Vandenbroucke $J P$, et al. The Strengthening the Reporting of Observational Studies in Epidemiology (STROBE) statement: guidelines for reporting observational studies. Lancet. 2007;370:1453-7.

18. Holm J, Håkanson E, Vánky F, Svedjeholm R. Mixed venous oxygen saturation predicts short- and long-term outcome after coronary artery bypass grafting surgery: a retrospective cohort analysis. Br J Anaesth. 2011;107:344-50.

19. Ranucci M, Isgrò G, Carlucci C, La Torre DT, Enginoli S, Frigiola A, et al. Central venous oxygen saturation and blood lactate levels during cardiopulmonary bypass are associated with outcome after pediatric cardiac surgery. Crit Care. 2010;14:R149. 
20. Laine GA, Hu BY, Wang S, Thomas Solis R, Reul Jr GJ. Isolated high lactate or low central venous oxygen saturation after cardiac surgery and association with outcome. J Cardiothorac Vasc Anesth. 2013;6:1271-6.

21. Levy B. Lactate and shock state: the metabolic view. Curr Opin Crit Care 2006;12:315-21.

22. Totaro RJ, Raper RF. Epinephrine-induced lactic acidosis following cardiopulmonary bypass. Crit Care Med. 1997;25:1693-9.

23. Raper RF, Cameron G, Walker D, Bowey CJ. Type B lactic acidosis following cardiopulmonary bypass. Crit Care Med. 1997;25:46-51.

24. Heringlake M, Wernerus M, Grünefeld J, Klaus S, Heinze H, Bechtel M, et al. The metabolic and renal effects of adrenaline and milrinone in patients with myocardial dysfunction after coronary artery bypass grafting. Crit Care 2007;11:R51.

25. Levy B, Gibot S, Franck P, Cravoisy A, Bollaert P-E. Relation between muscle $\mathrm{Na}+\mathrm{K}+$ ATPase activity and raised lactate concentrations in septic shock: a prospective study. Lancet. 2005;365:871-5.

26. White CW, Allarde RR. Oxygen saturation of jugular venous blood during external cardiac massage. South Med J. 1966;59:703-6.

27. Kastrup M, Carl M, Spies C, Sander M, Markewitz A, Schirmer U. Clinica impact of the publication of S3 guidelines for intensive care in cardiac surgery patients in Germany: results from a postal survey. Acta Anaesthesiol Scand. 2013:57:206-13.

28. Rivers E, Nguyen B, Havstad S, Ressler J, Muzzin A, Knoblich B, et al. Early goal-directed therapy in the treatment of severe sepsis and septic shock N Engl J Med. 2001;345:1368-77.

29. Polonen P, Ruokonen E, Hippelainen M, Poyhonen M, Takala J. A prospective, randomized study of goal-oriented haemodynamic therapy in cardiac surgical patients. Anesth Analg. 2000;90:1052-9.

30. Svenmarker S, Häggmark S, Östman M, Holmgren A, Näslund U. Central venous oxygen saturation during cardiopulmonary bypass predicts 3-year survival. Interact Cardiovasc Thorac Surg. 2013;16:21-6.

\section{Submit your next manuscript to BioMed Central and take full advantage of:}

- Convenient online submission

- Thorough peer review

- No space constraints or color figure charges

- Immediate publication on acceptance

- Inclusion in PubMed, CAS, Scopus and Google Scholar

- Research which is freely available for redistribution 